\title{
THE MEDIUM IS THE MESSAGE: FIREARM CALIBER AS A DETERMINANT OF DEATH FROM ASSAULT
}

\author{
FRANKLIN E. ZIMRING*
}

T

Hrs is the second report of a research project on violent assault in Chicago. The first, a study of fatal and nonfatal assaults with knives and guns, produced evidence to support three conclusions:

(1) Most homicide is not the result of a single-minded intention to kill at any cost.

(2) Many nonfatal attacks with knives and guns are apparently indistinguishable in motive, intent and dangerousness from many fatal attacks. Indeed, the overlap between fatal and nonfatal assaults with knives and guns is much more impressive than any differences that were noted.

(3) Weapon dangerousness, independent of any other factors, has a substantial impact on the death rate from attack. 1

This paper first reports on an attempt to carry the earlier research one step further by comparing low-caliber with high-caliber firearms attacks, and then suggests some ways in which the data developed in the two studies of

* Associate Professor of Law and Associate Director of the Center for Studies in Criminal Justice, University of Chicago. Jerald Kessler, now a third-year student at the University of Chicago Law School, performed with diligence and creativity as a research assistant on this project. Steven Harris, a second-year student at the Law School, conducted a helpful survey of the literature on intent in violent attack. The Chicago Police Department, in particular Mr. Michael Spiotto, provided access to the department files on reported fatal and nonfatal attacks that were used in this study.

1 Franklin E. Zimring, Is Gun Control Likely To Reduce Violent Killings?, 35 U. Chi. L. Rev. 721-24, 730-37 (1968). A third report, Homicide in Chicago, 1965-70, grows out of the same research project, a study of violent attack in Chicago supported by the Center for Studies in Criminal Justice at the University of Chicago. Other data on the issue of weapon dangerousness are developed in George D. Newton and Franklin $\mathbf{E}$. Zimring, Firearms and Violence in American Life (Staff Report (7) to the Nat'l Comm'n on the Causes and Prevention of Violence 1969). See, e.g., id. at 44 and 177-79 (relationship between relative degree of gun use and extent to which guns are more lethal than knives), 46-47 (death rates from gun vs. nongun armed robbery), 69-74 (effect of increase in gun ownership and use on death from assault in Detroit), 76-77 (relationship between relative gun use in robbery and assault in major cities). 
fatal and nonfatal attacks might interest criminologists and criminal law scholars.

\section{THE Study}

\section{A. Plan and Basic Data}

The previous study found that the rate of killings per hundred policereported attacks was five times as high with guns as with knives. ${ }^{2}$ This and other data indicated that most killings are coincident with a state of mind ambiguous enough so that the dange:ousness of the weapon used will have a significant influence on the chances that death will result. ${ }^{3}$ A second conclusion, flowing from the first, was that a shift from knives to guns or from guns to knives would have a significant impact on the death rate from violent attack.

If large-caliber firearms have a greater destructive potential than smallcaliber firearms, and there is every reason to believe they do, the comparison of the death rates from large-caliber and from small-caliber attacks provides one opportunity to confirm the earlier finding that weapon dangerousness had a significant impact on the death rate from assaults. If a difference in physical dangerousness does not result in a significant difference in the death rate from assault, this would be evidence that an actor's intentions rather than the mechanism he uses is the primary determinant of the death rate from violent assault. On the other hand, if, as is the case, attacks with different types of firearms have significantly different death rates, this lends important support to the theory that effective weapon controls can influence the homicide rate. Indeed, from a methodological standpoint, a firearm caliber comparison is not only an important support to the gun-versus-knife study alluded to earlier but an improvement on it because two kinds of gun attacks are easier to compare with respect to such data as the number of wounds and the location of wounds than knife and gun attacks.

The basic data for the caliber comparison come from an analysis of fatal and nonfatal firearm attacks reported to the Chicago Police between March 5 and July 22, 1970. In all, 1115 gun attacks resulting in 156 fatalities were reported to the police. In general profile, these firearm attacks present a picture of deadly attack in Chicago similar to that developed in the earlier study. Again, spontaneous fights and domestic and romantic altercations formed the principal backdrop to deadly attacks, ${ }^{4}$ and again nonfatal and fatal attacks were more notable for similarities in pattern than for any differences.

2 Franklin E. Zimring, supro note 1, at 728.

$81 d$. at $722-24,737$.

4 Id. at 721-25, especially tables 1-4. 
Table 1 compares fatal and nonfatal gun attacks with respect to the race and sex of victim, and race and sex of offender.

TABLE 1

Percentage Distribution of Homicide and Assautt Victoms, Offenders and Chicago Population

\begin{tabular}{|c|c|c|c|c|c|c|}
\hline & & \multicolumn{2}{|c|}{ Victims } & \multicolumn{2}{|c|}{ Offenders } & $\begin{array}{c}\text { Chicago } \\
\text { population } \\
\text { (1970 census) }\end{array}$ \\
\hline White & & Fatal & Nonfatal & Fatal & Nonfatal & \\
\hline Black & $\begin{array}{c}\text { Male } \\
\text { Female }\end{array}$ & $\begin{array}{r}17 \\
2\end{array}$ & $\begin{array}{r}11 \\
1\end{array}$ & $\begin{array}{l}7 \\
2\end{array}$ & $\begin{array}{l}8 \\
1\end{array}$ & $\begin{array}{l}32 \\
35\end{array}$ \\
\hline \multirow{3}{*}{ Fispanic } & $\begin{array}{c}\text { Male } \\
\text { Female }\end{array}$ & $\begin{array}{l}61 \\
13\end{array}$ & $\begin{array}{l}71 \\
13\end{array}$ & $\begin{array}{r}79 \\
7\end{array}$ & $\begin{array}{r}77 \\
9\end{array}$ & $\begin{array}{l}15 \\
18\end{array}$ \\
\hline & $\begin{array}{c}\text { Male } \\
\text { Female }\end{array}$ & $\begin{array}{l}5 \\
3\end{array}$ & $\begin{array}{l}4 \\
1\end{array}$ & $\begin{array}{l}6 \\
0\end{array}$ & $\begin{array}{l}6 \\
0\end{array}$ & $\begin{array}{l}2 \\
2\end{array}$ \\
\hline & & $\begin{array}{l}100 \% \\
(156)\end{array}$ & $\begin{array}{l}100 \% \\
(932)\end{array}$ & $\begin{array}{l}100 \% \\
(135)\end{array}$ & $\begin{array}{l}100 \% \\
(815)\end{array}$ & $\begin{array}{c}\overline{100 \%} \\
(3,366,957)\end{array}$ \\
\hline
\end{tabular}

1 Less than .5\%.

- Not avaithble-included in "white."

Source: Compiled from Chicago Police Dep'l Offense Reports.

The distribution by race and sex of victims of fatal gun assaults is quite similar to the distribution of victims of nonfatal gun assaults, and very different from the distribution of the population. The implication is that these two classes of attack are part of a single larger class. This also seems to be a plausible inference from the race and sex data on offenders in Table 1, where again wounders and killers are similar to each other and different from the general population.

Table 2 compares the incidents leading up to the attack for fatal versus nonfatal attacks, in all categories except robbery, which will be separately considered.

Table 2, like the data on the distribution of attacks by race and sex, supports the theory that there is a great deal of continuity between fatal and nonfatal gun attacks because, generally, the same type of circumstances lead to woundings and death. In this comparison, however, there are differences as well as similarities. Domestic and romantic arguments account for a quarter of all killings but only one out of every ten nonfatal attacks, while "teen gang" offenders account for 17 per cent of all nonfatal attacks but only 11 per cent of fatalities. These differences may seem to suggest that domestic attacks are more deadly than others. But it would be incorrect to draw such an inference. Domestic fights that kill must come to the attention of the police. Nonfatal 
TABLe 2

Gun Attacks by Circumstances

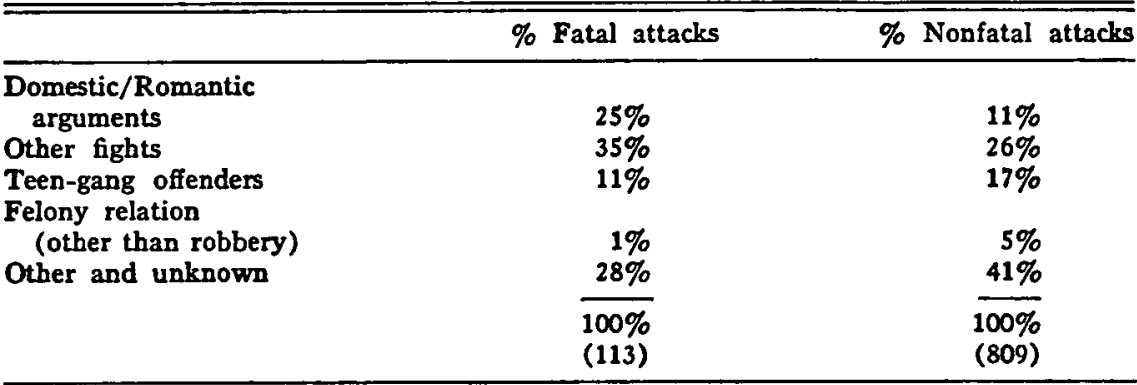

Source: Compined from Chicago Police Dep't Offense Reports.

attacks, particularly if the injury is not very severe, may not be reported to the police; and such attacks, when they occur within the family, are more apt to go unreported than other such attacks because of the close relationship between the victim and offender.

Table 3 sets out the distribution of gun attacks by circumstances leading to the attack for the different gun caliber categories that will be the basis for comparison in this study.

TABLE 3

Gon attacks by Caliber by Circumstances

\begin{tabular}{lccc}
\hline \hline & 22 & .25 and 32 & 38 \\
\hline Domestic/Romantic & $23 \%$ & $23 \%$ & $27 \%$ \\
$\quad$ altercations & $39 \%$ & $37 \%$ & $34 \%$ \\
Other fights & $15 \%$ & $8 \%$ & $14 \%$ \\
Teen-gang offender & $2 \%$ & $5 \%$ & $5 \%$ \\
$\begin{array}{l}\text { Felony relation } \\
\text { (other than robbery) }\end{array}$ & $21 \%$ & $27 \%$ & $20 \%$ \\
Other & $100 \%$ & $100 \%$ & $100 \%$ \\
& $(155)$ & $(126)$ & $(109)$ \\
\hline
\end{tabular}

Source: Compiled from Chicago Police Deg't Offense Reports.

The data reported in Table 3 point clearly to the conclusion that the circumstances leading to attacks with different caliber guns are remarkably similar.

5 One recent study found that only $22 \%$ of assaults where the offender was a relative of the victim were reported, compared to $72 \%$ of all other assaults. While a much higher percentage of gun assaults would tend to be reported, the "family" effect might still be great. See Anthony Turner, The San Jose Methods Test of Known Crime Victims (unpublished from U.S. Law Enforcement Assistance Admin. Statistics Div. 1971). 
Other findings from this sample, consistent with the 1968 study, ${ }^{6}$ include the relatively small number of gun killings that involve more than one wound (38 per cent in this sample) and the similarity in the number and location of wounds between many nonfatal gun attacks and most gun homicides.

\section{B. Weapon-Caliber Effects}

In order to obtain data on weapon-caliber effects, two minor problems and one major problem in the data had to be overcome. A minor problem was that certain types of weapons, most notably shotguns, cannot be easily compared with other types of firearm. Our solution to this problem was to exclude shotgun attacks ( 12 per cent of all attacks) and large-caliber rifle attacks (less than one per cent of attacks). A second problem was that information was not available, for the entire period covered by the rest of the study, on robberies that result in nonfatal rather than fatal wounds. To deal with this problem, data on fatal robberies (19 per cent of all fatalities) were excluded from the main study and separately analyzed.?

These exclusions left us with a sample of 932 cases, the great majority of them attacks made with handguns. ${ }^{8}$ Table 4 reveals the major problem associated with drawing inferences in this group of cases about the effects of weapon

- See Franklin E. Zimring, supra note 1, at 731 (table 7), 734.

7 The problem with robbery-assault statistics is that, typically, if a victim lives, the incident is reported as a robbery and stored in a different record section of the police department. Data were available, however, on fatal robberies during the four police periods, and the distribution by caliber is somewhat different from that noted in other offenses.

\begin{tabular}{lcc} 
Robbery & $\begin{array}{c}\text { Nonrobbery } \\
\text { killings }(\%)\end{array}$ & $1 \%$ \\
.22 & 11 & 24 \\
.25 killings (\%) & .32 & 26 \\
.38 and $>.38$ & 62 & 51 \\
\hline $100 \%(27)$ & $100 \%(109)$
\end{tabular}

At the same time, a greater number of robbery killings involved multiple wounds, as shown below.

\begin{tabular}{lcc}
$\begin{array}{c}\text { Robbery } \\
\text { killings }\end{array}$ & $\begin{array}{c}\text { All other } \\
\text { killings }\end{array}$ \\
Multiple wound & 48 & 62 \\
& 52 & 38 \\
\hline $100 \%(27)$ & $100 \%(109)$
\end{tabular}

These data may suggest more deadly intention in robbery or a greater necessity for force growing out of victim resistance in robbery. The answer to whether a profound caliber effect exists awaits data on nonfatal robbery shootings.

8 All .22-caliber attacks were included even if there was a police notation that a rifle was involved. 
TABLE 4

\begin{tabular}{lcc}
\hline & Fatal attacks & Nonfatal attacks \\
\hline Caliber known & $94 \%$ & $37 \%$ \\
Caliber not known & $6 \%$ & $63 \%$ \\
& $100 \%$ & $\frac{100 \%}{(797)}$ \\
\hline
\end{tabular}

Source: Chicaso Police Dep't Offense Reports.

caliber on death rates: the substantial number of cases in which weapon caliber is not known. The reason why caliber is known in far fewer aggravated assaults than homicides is doubtless that less police effort is devoted to nonfatal attacks; just as among nonfatal attacks, the more serious the wound the more likely that caliber is known. ${ }^{9}$

An analysis of particular types of firearm attacks, however, provides evidence that the sample of attacks for which caliber is known is an acceptably representative sample of all firearm attacks by caliber. Attacks that result from domestic altercations will involve both a victim and offender apt to be familiar with household firearms, as well as a readily available suspect, and thus promise a much higher percentage of cases in which firearm caliber is known. Thus, firearm caliber was determined in 92 per cent of the 65 domestic altercation cases compared to 40 per cent of all other types of cases. Table 5 compares the distribution of attacks by caliber when caliber is known for

TABLE 5

\begin{tabular}{cccccr}
\hline \hline & \multicolumn{2}{c}{ Small caliber } & \multicolumn{3}{c}{ Large caliber } \\
\hline $\begin{array}{c}\text { Domestic attacks } \\
\text { (92\% Caliber known) }\end{array}$ & .22 & .25 & .32 & .38 & $>.38$ \\
Other attacks & $33 \%$ & $16 \%$ & $19 \%$ & $29 \%$ & $3 \%$ \\
(40\% Caliber known) & & & & & \\
& .22 & .25 & .32 & .38 & $>38$ \\
& $38 \%$ & $12 \%$ & $15 \%$ & $29 \%$ & $5 \%$
\end{tabular}

Source: Compiled from Chicago Police Dep't Offense Reports.

domestic altercations and all other altercations. In spite of the great differences in the percentage of attacks in which caliber is known, the percentage distribution by caliber is remarkably similar. ${ }^{10}$

9 Comparing the percentage of nonfatal attacks in the sámple where caliber is known for single-shot attacks to various parts of the body, we come up with these results:

$\begin{array}{ll}\text { Head and chest } & 44 \% \\ \text { Abdomen, back and neck } & 38 \% \\ \text { Shoulder, arm and leg } & 31 \%\end{array}$

10 The death rate difference by caliber is just as pronounced in domestic disputes; see Table 8, infra. 
With that preliminary question discussed, it is possible to proceed to an analysis of death rates from firearm attacks by caliber. The simplest way of making this comparison is to compare the death rate per 100 police-reported firearms attacks for each of the four major firearm calibers. But the simple method of comparison overstates the independent effects of weapon caliber, because a greater number of large-caliber handgun attacks result in multiple wounds than do small-caliber guns. Table 6 takes a slightly more complicated route by presenting, for all attacks in which firearm caliber was identified, the percentage of single-wound attacks to each of three regions of the body that result in death, and a similar comparison for attacks that involve multiple wounds.

TABLE 6

Percentage of Krown Cautber Atracrs That Result in Death

\begin{tabular}{|c|c|c|c|c|c|}
\hline & \multicolumn{5}{|c|}{ Single wound } \\
\hline & .22 & .25 & .32 & 38 & $>.38$ \\
\hline Head and chest & $\begin{array}{l}36 \% \\
(34)\end{array}$ & $\begin{array}{l}70 \% \\
(10)\end{array}$ & $\begin{array}{l}67 \% \\
(12)\end{array}$ & $\begin{array}{l}76 \% \\
(29)\end{array}$ & $\begin{array}{c}83 \% \\
(6)\end{array}$ \\
\hline Abdomen, back, neck & $\begin{array}{l}35 \% \\
(26)\end{array}$ & $\begin{array}{c}29 \% \\
(7)\end{array}$ & $\begin{array}{l}10 \% \\
(10)\end{array}$ & $\begin{array}{l}38 \% \\
(13)\end{array}$ & - \\
\hline \multirow[t]{3}{*}{ Shoulder, arm, leg } & $\begin{array}{r}0 \% \\
(55)\end{array}$ & $\begin{array}{r}5 \% \\
(22)\end{array}$ & $\begin{array}{r}0 \% \\
(17)\end{array}$ & $\begin{array}{r}0 \% \\
(27)\end{array}$ & $\begin{array}{l}0 \% \\
(4)\end{array}$ \\
\hline & \multicolumn{5}{|c|}{ Multiple wound } \\
\hline & .22 & .25 & 32 & .38 & $>38$ \\
\hline Head and chest & $\begin{array}{l}36 \% \\
(14)\end{array}$ & $\begin{array}{c}33 \% \\
(6)\end{array}$ & $\begin{array}{l}46 \% \\
(13)\end{array}$ & $\begin{array}{l}77 \% \\
(26)\end{array}$ & $\begin{array}{c}100 \% \\
\text { (2) }\end{array}$ \\
\hline Abdomen, back, neck & $\begin{array}{l}0 \% \\
(5)\end{array}$ & $\begin{array}{l}50 \% \\
(2)\end{array}$ & $\begin{array}{c}33 \% \\
(6)\end{array}$ & $\begin{array}{c}33 \% \\
(6)\end{array}$ & - \\
\hline Shoulder, arm, leg & $\begin{array}{l}0 \% \\
\text { (2) }\end{array}$ & $\begin{array}{l}0 \% \\
\text { (1) }\end{array}$ & - & $\begin{array}{l}0 \% \\
(7)\end{array}$ & - \\
\hline
\end{tabular}

Source: Compiled from Chicaso Police Dep't Offense Reparts.

Table 6 overstates the probability that a wound with a particular caliber firearm to a particular area will result in fatality, because nonfatal attacks for which the caliber is unknown have been excluded and inclusion of these attacks would reduce the fatality percentage considerably across the board. However, by adding information about the number and location of wounds in attacks in which the police did not identify weapon caliber, the data presented in Table 6 can be converted into an estimate of the different death rates expectable per 100 police-reported attacks made with various types of gun to different areas of the body. Table 7 attempts this estimate by distributing unknown-caliber nonfatal attacks by caliber in the pattern found in nonfatal 
assaults where caliber was known. The seven fatal assaults with unknown caliber were ignored. ${ }^{11}$

TABLE 7

Estracated Death Rate prom Gun Attacks by Wound Location, Number of Wounds, and Gun Calmer

\begin{tabular}{|c|c|c|c|c|c|}
\hline & \multicolumn{5}{|c|}{ Single wound } \\
\hline & .22 & .25 & 32 & .38 & $>.38$ \\
\hline Head and chest & $\begin{array}{l}16 \% \\
(69)\end{array}$ & $\begin{array}{l}50 \% \\
(14)\end{array}$ & $\begin{array}{l}44 \% \\
(18)\end{array}$ & $\begin{array}{l}55 \% \\
(40)\end{array}$ & $\begin{array}{c}63 \% \\
(8)\end{array}$ \\
\hline Abdomen, back, neck & $\begin{array}{l}17 \% \\
(52)\end{array}$ & $\begin{array}{l}13 \% \\
(15)\end{array}$ & $\begin{array}{r}4 \% \\
(24)\end{array}$ & $\begin{array}{l}20 \% \\
(25)\end{array}$ & $\begin{array}{c}25 \% \\
(4)\end{array}$ \\
\hline Shoulder, arm, leg & $\begin{array}{c}0 \% \\
(170)\end{array}$ & $\begin{array}{l}2 \% \\
(71)\end{array}$ & $\begin{array}{r}0 \% \\
(52)\end{array}$ & $\begin{array}{r}0 \% \\
(83)\end{array}$ & $\begin{array}{r}0 \% \\
\text { (11) }\end{array}$ \\
\hline \multirow[t]{3}{*}{ Total } & $\begin{array}{c}7 \% \\
(291)\end{array}$ & $\begin{array}{l}10 \% \\
(100)\end{array}$ & $\begin{array}{l}10 \% \\
(94)\end{array}$ & $\begin{array}{r}18 \% \\
(148)\end{array}$ & $\begin{array}{l}27 \% \\
(23)\end{array}$ \\
\hline & \multicolumn{5}{|c|}{ Multiple wound } \\
\hline & .22 & .25 & .32 & .38 & $>.38$ \\
\hline Head and chest & $\begin{array}{l}28 \% \\
(19)\end{array}$ & $\begin{array}{c}25 \% \\
(4)\end{array}$ & $\begin{array}{l}35 \% \\
(17)\end{array}$ & $\begin{array}{l}68 \% \\
(25)\end{array}$ & $\begin{array}{c}100 \% \\
(2)\end{array}$ \\
\hline Abdomen, back, neck & $\begin{array}{c}0 \% \\
\text { (11) }\end{array}$ & $\begin{array}{c}33 \% \\
(3)\end{array}$ & $\begin{array}{l}18 \% \\
\text { (11) }\end{array}$ & $\begin{array}{l}18 \% \\
\text { (11) }\end{array}$ & - \\
\hline Shoulder, arm, leg & $\begin{array}{l}0 \% \\
(6)\end{array}$ & $\begin{array}{l}0 \% \\
(3) \\
\end{array}$ & - & $\begin{array}{l}0 \% \\
(22)\end{array}$ & 一 \\
\hline Total & $\begin{array}{l}14 \% \\
(36)\end{array}$ & $\begin{array}{l}20 \% \\
(10)\end{array}$ & $\begin{array}{l}29 \% \\
(28)\end{array}$ & $\begin{array}{l}40 \% \\
(58)\end{array}$ & $\begin{array}{c}100 \% \\
\text { (2) }\end{array}$ \\
\hline
\end{tabular}

Source: Compiled from Chicago Police Dep't Ofiense Reports.

Table 7 reveals three discrete influences on the fatality rate from firearm attacks. The first is the location of the most serious wound inflicted by a

11 There are three ways in which the estimate could have been made. An three involve using information available about the number and location of wounds and estimating the distribution of attacks by caliber. One method would assume the distribution of all known attacks to be the pattern to be found in all unknown attacks. This assumes no bias by caliber in the sample of known-caliber attacks. A second method would assume that the pattern of domestic assaults by caliber was the same as all other assaults and would allocate all unknown-caliber attacks in each wound location by caliber so that the total percentage for each caliber was the same as that caliber's share of domestic disputes. This method was rejected because of the likelihood that it would understate the number of 22 -caliber attacks. Only $11 \%$ of all domestic killings were 22 killings, suggesting that the percentage of .22 assaults was higher in nondomestic attacks than in domestic attacks. The third method would distribute the unknown-caliber attacks to reflect the distribution of nonfatal attacks by caliber when caliber is known. Thus, if .22-caliber attacks are $30 \%$ of total attacks and $35 \%$ of nonfatal attacks, the first method would assume that $30 \%$ of all unknown-caliber attacks were .22, while the third method would assume that $35 \%$ were 22 attacks. Since caliber is an influence on whether or not death results, and since whether death results is an influence on whether caliber is determined, the third method seems superior to the second. 
particular attack. A simple rule of thumb would be that, independent of caliber and number of wounds, attacks that result in wounds to the head and chest are three times as deadly as gun attacks that result in wounds only to the abdomen, neck, or back. Attacks in which the most serious wound is to the shoulder, arm, or leg are rarely fatal.

A second relationship that emerges from considering Table 7 is that the number of wounds inflicted in a firearm attack has predictive value as to the death rate. The death rate for multiple-wound attacks where the most serious wound was to the head or chest is higher than the rate for single wounds to the head or chest, and clearly is much higher than if the offender had stopped after his first wound, which may have hit a less dangerous area. With respect to both the location of the wound and the number of wounds inflicted, it is difficult to judge how many of the effects noted are independent of the intention of the attacker and how many reflect a tendency of individuals with more homicidal intentions to wound more often and shoot to more vital areas of the body.

The third major predictive relationship that can be noted is that of weapon caliber. The two most widely used weapon calibers, .22 and .38 , present the most meaningful contrast. Examination of Table 7 shows a much greater fatality rate from .38 caliber attacks resulting in more than one wound and from single-wound .38 caliber attacks to the head and chest region. Because these areas account for most fatalities, the overall result is that .38 caliber attacks are more than twice as deadly as .22 caliber attacks. Among the less commonly used weapons, .25 and .32 caliber firearms are more likely to kill than .22 's by a considerable margin and less likely to kill than .38 caliber attacks. No significant differences between the two intermediate calibers emerge from the present data. The few attacks made with weapons greater than .38 caliber exhibit the highest of all fatality rates, but the number of attacks with such weapons is too small to justify a conclusion that such weapons are significantly more dangerous than the .38 .

Because some of the estimates are based on a small number of known attacks-notably those dealing with intermediate-caliber and larger-than-.38 caliber weapons, and with most multiple-wound attacks-Table 7 is merely a first approximation of the relative deadliness of attacks by caliber, wound location and number of wounds. But with respect to .22 and .38 caliber attacks, particularly single-wound attacks, the numbers are large and the contrast is. striking.

There is a further way of estimating the magnitude of weapon caliber effects on deadly attacks: projecting the impact of caliber effects on Chicago's homicide experience. Using the data developed in Table 7, we can approximate the total potential impact of caliber effects on the death rate from gun attacks. 
FIGURE 1

Caliber Ertects on Fatalities from Gun assault

\begin{tabular}{|c|c|c|}
\hline Number of fatalities if all attacks were with .38 & $177(+62 \%)$ & +620 \\
\hline Actual number of fatalities from gun attacks & 109 & \\
\hline Number of fatalities if all attacks were with .22 & $57(-48 \%)$ & \\
\hline
\end{tabular}

\section{Alternatives to the Instrumentality Interpretation}

One alternative to concluding that there is a substantial instrumentality effect tied to weapon caliber is the possibility that caliber differences either mask or express differences in intention sufficient to explain a two-to-one difference in death rate. At the outset, it is difficult to understand how much range in intention is possible when we are comparing single-shot wounds to the head or chest with one type of firearm as against single-shot wounds to the head or chest with another type of firearm. But to the extent that such comparison allows for differences in intention, some data are available to suggest that the differences are not great. For one thing, the number of individuals who can choose between small- and large-caliber weapons at the time of an attack, thereby expressing differential intent by opting for a highor low-caliber weapon, is small. ${ }^{12}$ The number of handgun owners who own more than one such weapon is estimated at slightly fewer than one out of five, and there is no firm evidence available on whether persons apt to be involved in deadly attacks are multiple handgun owners more of ten than the average. ${ }^{13}$

It can be argued, however, that there is a differential expression of personality involved in choosing large- versus small-caliber handguns that reaches back to the time of purchase when caliber decision is made and therefore is not affected by the fact that most handgun owners own only one. According to this view, there are ".38-caliber people" and they are somewhat more deadly than ".22-caliber people," independent of the difference in the dangerousness of their weapons. The difference in the number of multiple-wound attacks between .22-caliber weapons and the higher-caliber weapons leaves

12 This assumes, of course, that most gun attacks are not sufficiently premeditated so that persons can run out and purchase weapons with suitable calibers for their particular purposes. See pp. 98-100, supra, and Franklin E. Zimring, supra note 1.

13 Of those individuals who report handgun ownership, $83 \%$ report owning one such gun. See George P. Newton and Franklin E. Zimring, supra note 1, at 176. A study of prison inmates in Texas and Louisiana reports high lifetime handgun ownership. Study by C. M. Friel, Sam Houston State College (unpublished, 1970). The study, however, does not indicate whether multiple ownership is common or turnover high. Nor do the data distinguish between inmates who have committed crimes of violence and other inmates. 
some room for this kind of argument, but not much; and the larger number of .22 single-shot attacks is explainable, in part, by the fact that some .22 -caliber rifles have only a one-shot capacity, and .22-caliber rifles may form a significant sprinkling in the attacks noted. ${ }^{14}$ Yet the differences in proportion of multiple-wound attacks by caliber do suggest some difference in intent correlated with caliber. In sum, there is no basis for rejecting out of hand the notion that differential intention or personality may play some role in gross intercaliber differences in death rate-but there is also no reason to suppose that personality effects can create a two-to-one difference in death rate after controlling for the number and location of wounds.

One method of further assessing the relative importance of caliber selection would be to see whether the intercaliber death rate differences hold up in domestic disputes, which are particularly interesting because they involve the most substantial probability that the actor is using a gun for a different purpose from that which motivated gun purchase. Yet Table 8 shows the same order of death rate difference by caliber for domestic attacks that Table 7 showed for all attacks.

TABLE 8

Deatg Rates by Cautber, Nonger or Wounds and Location in Domestic Attacks

\begin{tabular}{|c|c|c|c|c|}
\hline & \multicolumn{4}{|c|}{ Single wound } \\
\hline & .22 & $.25 \& .32$ & 38 & $>.38$ \\
\hline \multirow[t]{2}{*}{$\begin{array}{l}\text { Head and chest } \\
\text { Abdomen, back and neck } \\
\text { Total vital areas }\end{array}$} & $\begin{array}{l}0 \% \\
0 \% \\
0 \%(8)\end{array}$ & $\begin{array}{l}100 \% \\
0 \% \\
33 \%(6)\end{array}$ & $\begin{array}{l}67 \% \\
50 \% \\
57 \%(7)\end{array}$ & $\frac{50 \%}{(2)}$ \\
\hline & .22 & $\begin{array}{l}\text { Multip } \\
25 \& .32\end{array}$ & ind 38 & $>38$ \\
\hline $\begin{array}{l}\text { Head and chest } \\
\text { Abdomen, back and neck } \\
\text { Total vital areas }\end{array}$ & $\begin{array}{l}40 \% \\
0 \% \\
29 \%(7)\end{array}$ & $\begin{array}{l}60 \% \\
0 \% \\
50 \%(6)\end{array}$ & $\begin{array}{l}75 \% \\
100 \% \\
78 \%(9)\end{array}$ & - \\
\hline
\end{tabular}

Sowrce: Compiled from Chicago Police Dep't Offeese Reports.

Another interesting comparison is obtained by analyzing separately the outcome of shooting episodes involving female offenders, on the ground that the female offender is least likely to have selected her own weapon and most likely to have acquired someone else's weapon under circumstances that leave little room for suggesting that she chose a particular caliber in line with either a personality trait or short-range intention. Table 9 presents data on attacks by females, and tells the same story as its predecessors.

14 See note 8 supra. 
TABLE 9

Deatz Rates from Attacks to Vital Areas by Female Assatuarts

\begin{tabular}{|c|c|c|c|c|}
\hline & \multicolumn{4}{|c|}{ Single wound } \\
\hline & .22 & $.25 \quad \& \quad .32$ & .38 & $>.38$ \\
\hline \multirow[t]{3}{*}{$\begin{array}{l}\text { Head and chest } \\
\text { Abdomen, back and neck } \\
\text { Total vital areas }\end{array}$} & $\begin{array}{l}0 \% \\
0 \% \\
0 \%(9)\end{array}$ & $\begin{array}{l}50 \% \\
25 \% \\
33 \%(6)\end{array}$ & $\begin{array}{l}50 \% \\
100 \% \\
67 \%(3)\end{array}$ & $\frac{50 \%}{50 \%(2)}$ \\
\hline & \multicolumn{4}{|c|}{ Multiple wound } \\
\hline & .22 & $.25 \& .32$ & 38 & $>.38$ \\
\hline $\begin{array}{l}\text { Head and chest } \\
\text { Abdomen, back and neck } \\
\text { Total vital areas }\end{array}$ & $\begin{array}{l}33 \% \\
0 \% \\
20 \%(5)\end{array}$ & $\begin{array}{l}50 \% \\
100 \% \\
67 \%(3)\end{array}$ & $\frac{67 \%}{67 \%(3)}$ & - \\
\hline
\end{tabular}

Source: Compiled from Chicago Police Dep't Offense Reports.

These small sample checks are consistent with the argument presented above: there are intriguing differences at the margin between high-caliber and low-caliber handgun attacks. But the major differences in death rates appear to be instrumentality effects.

\section{Some Implications of the Weapons Studies}

The narrow purpose of the present study was to investigate further the question of weapon effects in violent assault. It confirms the earlier conclusion that the instrument used in an attack has a strong impact on chances of fatality. A corollary is that weapon controls, to the extent effective, could save many lives in Chicago. A broader aim of this series of studies was to seek meaningful knowledge about deadly assault in our major cities. And, with two detailed studies of attack in Chicago and a number of collateral inquiries completed, ${ }^{15}$ the time seems ripe to discuss what, if anything, these data might teach us about understanding and preventing violent killings. In what follows, some observations are grouped under three rubrics:

A. The character of intent in violent assault.

B. The exportability of Chicago-based data to other areas.

C. The implications of the data for criminal law scholarship and reform.

\section{A. The Character of Intent in Violent Assault}

Professor Megargee, one of many scholars who have addressed the social implications of violent activity, emphasizes both the importance and the frustrations of focusing on the role of intent in deadly assault when he says:

The second issue confronting those who would define violence is the question of

15 See George P. Newton and Franklin E. Zimring, supro note 1, at ch. 7. 
intentionality. Intentionality by its very nature is something that cannot be observed. Our insights into human behavior have shown that there is no hard and fast line between what is intended and what is not intended. ${ }^{16}$

Lacking that hard and fast line, Megargee continues:

Typologies of violence offered by behavioral scientists have focused more on the motivation of the violent person than on the actual act. ${ }^{17}$

He goes on to suggest:

This focus recognizes that the difference between murder and aggravated assault often depends on whether a bullet chances to hit a muscle or an artery or on whether a physician is nearby to treat the victim. ${ }^{18}$

At this point I am moved to disagree, not with Megargee's good sense, but with his generous treatment of his colleagues. In fact, sociological students of homicide, perhaps gulled by their legal colleagues, have at times assumed that homicide is a separate, autonomous category of intentional human behavior. A classic example of this kind of assumption can be found in Wolfgang's Patterns of Criminal Homicide:

It is the contention of this observer that few homicides due to shootings could be avoided merely if a firearm were not immediately present, and that the offender would select some other weapon to achieve the same destructive goal. Probably only in those cases where a felon kills a police officer, or vice versa, would homicide be avoided in the absence of a firearm.19

Wolfgang's remarks should not be taken out of context. Elsewhere in his study there is a suggestion that something other than differences in intent might distinguish criminal killing from less destructive acts of violent attack. For example, he observes that the means used by Irish immigrants to attack, principally by brass knuckles and fists, may help to explain the low death rate from those attacks. ${ }^{20}$

Other studies of criminal homicide tend to be even easier in assuming a distinctive intentional component to homicidal impulse. David Abrahamsen devotes chapter 10 of his book, The Psychology of Crime, to "the personality of the murderer." His discussion, which is in terms of the offender's "wish to

16 Edwin I. Megargee, A Critical Review of Theories of Violence, in Donald Mulvihill, Melvin Tumin, and Lynn Curtis, Crimes of Violence 1039 (Staff Report (13) to the Nat'] Comm'n on the Causes and Prevention of Violence 1969).

17 Id. at 1043 .

18 Ibid.

19 Marvin Wolfgang, Patterns of Criminal Homicide 83 (1958).

$20 \mathrm{Id}$. at 80. 
kill" and "the force which compels a person to commit homicide,"21 may be the consequence of implicitly assuming that homicidal force is an autonomous mechanism of human expression and homicidal result its usual product.

We also find in the sociological literature studies of the cultural and psychological backgrounds to violent behavior that serve as a counterweight to the implicit assumptions in homicide studies. Nine years after Patterns in Criminal Homicide, Wolfgang and Ferracuti speak in terms of the subculture of violence rather than the subculture of homicide. ${ }^{22}$ Hans Toch, in his Violent $M e n,{ }^{23}$ seems implicitly to assume a great deal of continuity between fatal and nonfatal violent episodes, yet Toch never addresses the question whether homicide and less drastic forms of violence are either similar or different; rather, he discusses violence as a generic behavioral category.

This is not to say that those who are skeptical about the autonomy of homicide as a pattern of human behavior have lacked evidence for their skepticism. Pittman and Handy noted, in 1964, that a

comparison of findings concerning acts of homicide and aggravated assault indicates that the pattern for the two crimes is quite similar. Both acts, of course, are reflections of population subgroupings which tend to externalize their aggression when confronted with conflict situations. ${ }^{24}$

Until recently, however, what Professor Megargee calls the "question of intentionality" has been far from the central focus of sociological concern in the study of violence. In general, it has been a question addressed parenthetically by the otherwise employed social scientist.

The knife-versus-gun and gun-caliber studies support three related propositions about the role of intent in violent assault. The first is that there is a good deal of overlap between the structure, intention and motivational background of most serious but nonfatal attacks and most homicides in Chicago. Given the prior findings on the demographic similarity, with respect to victims and offenders, of homicide and aggravated assault, this should come as no surprise. But the conclusion is, in a special way, inescapable in the present data: for example, whatever else may separate fatal from nonfatal firearm attacks, the element of chance must play an important role, because all attacks to the head and trunk can cause death (but less than a majority do) and more than 60 per cent of all lethal attacks are single-wound shootings. The overlap

21 David Abrahamsen, The Psychology of Crime 185 (1960).

22 Marvin Wolfgang and Franco Ferracuti, The Subculture of Violence (1967).

23 Hans Toch, Violent Men (1969).

24 David J. Pittman and William Handy, Patterns in Criminal Aggravated Assault, 55 J. Crim. L., Criminology \& Police Science 462, 470 (1964). 
I speak of is a physical reality, not simply the fact that the same sort of people engage in both behaviors. Nor is it merely the finding that some assailants and some killers appear to be acting in the same way. Rather, it is a strong suggestion that most people who attack with guns act in ways that are distinguishable only on the basis of result.

Discussion of the overlap between fatal and nonfatal attacks leads to the second major inference that can be drawn from the two studies under discussion: that most violent attacks with deadly weapons, whether fatal or nonfatal, are pursued with ambiguous intentions as to whether the victim should die. Most of the attacks we have studied that resulted in wounds to the head or trunk of a victim were inflicted under circumstances consistent with assuming that the offender considered death as one of the likely consequences of his actions. The same can almost certainly be said for a number of attacks that resulted in wounding to less vital body areas, although a precise estimate of the proportion of woundings to extremities that involved appreciation of the risk of death is unobtainable. Even if the risk of death was realized, it is still the case that this result was not diligently pursued in the majority of deadly attacks. In 62 per cent of all fatal firearm attacks, and 72 per cent of all nonfatal firearm attacks, the offender did not inflict more than one wound, in spite of his ordinary ability to do so. To some extent these statistics may be telling us that the initial intention, in both fatal and nonfatal gun assaults, is to achieve, by wounding, an objective other than death, but to achieve that objective whether or not death occurs.

There are suggestions in the prior literature that the ambiguously motivated deadly assault may play a role in homicide statistics. With respect to homicide by beating, Wolfgang says:

Many of these ... appear to have been the result of fighting with no intention on the part of the offender to kill. ${ }^{25}$

What is missing in the literature is a study of data bearing on intention with respect to both fatal and nonfatal attacks. Without such data it would be impossible, regardless of what intuitive power might have been brought to bear on the question, to make statements about most killings or most nonfatal woundings unless the circumstances of an attack pointed unambiguously to the fact that death was or was not intended with some energy. ${ }^{28}$ If, as I have suggested, most attacks that kill—as well as most attacks that do not kill-are

25 Marvin Wolfgang, supra note 19 , at 86.

26 But see David Abrahamsen, supra note 21, at 185:

A murderer is so completely dominated by his inner forces that apparently no means is too foul for achieving his goal, as seen in the following case. 
intended ambiguously, this is a difficult conclusion to reach without comparing fatal and nonfatal attacks in some detail. And that comparison is a relatively recent arrival in the sociological literature on violence.

One final possibility should be discussed. While there is evidence that the objective of a serious attack is ambiguous at the outset and remains so throughout its course, there is also some indication that the desired result of an attack may very well change during its enactment. The act of firing a gun alters the emotional context of the situation in a number of ways that can change the attacker's objectives:

-Firing a shot that finds its mark can be an emotional release, and this release can make an individual who might have sought or at least ignored the possibility of his victim's death more inclined to end his attack.

-Firing a shot and inflicting a wound also alter the immediate conflict situation that leads to an attack, and if the wound is serious or stunning, the threat of attack or counterattack by the victim may be abated.

-At the same time, inflicting a wound has transferred the consequences of assault from the realm of fantasy to that of palpable and unpleasant reality; if the reality of deadly attack does not square with its fantasy significance, or involves emotional costs greater than the attacker contemplated, the attack may be aborted, even if it was originally pursued with lethal intent.

\section{B. The Limits of Instrumentality Explanations}

The present study maintains an extremely narrow focus: attacks with one type of weapon (guns) in one city over a four month period. One natural issue early in the sequence of any discussion of these data is the extent to which the significant instrumentality effect found here can be expected to occur with other types of weapons and in other locations. Our tentative answer on this issue is the following hypothesis:

The significance of weapon dangerousness on the death rate will rise or fall with the proportion of ambiguously motivated attacks with deadly weapons.

This hypothesis comes, rather unmysteriously, from the interrelation discussed earlier between the large number of ambiguously motivated deadly attacks and the extensive instrumentality effects in such attacks. Because the hypothesis is phrased in terms of differential intentions, some more tangible form of prediction will be necessary before it can be tested through the use of comparative criminal statistics.

The hypothesis speaks only to the relative differences one might observe in different settings. It does not suggest that there is any city where increases or decreases in the use of guns will not affect the death rate from assault. But 
the theory highlights two apparent ironies. The first is that as the rate of ambiguously motivated attacks with guns increases, the rate of gun deaths per 100,000 persons will increase but the death rate per 100 gun assaults, if anything, should decrease somewhat. ${ }^{27}$ The second apparent irony is that gun controls are most needed in precisely those situations where guns have the greatest popularity in attacks-and thus where control will be hardest to achieve. This is not to say that the need for firearms control is meaningfully correlated with ownership and use of firearms alone. Rather, the combination of widespread gun ownership, particularly handgun ownership, and the propensity to use these weapons is the explosive compound.

\section{Criminal Law for a Subculture of Violence}

The task of relating data from these studies to issues in substantive criminal law is an open-ended one. At this point it is more appropriate to raise most of the following points as plausible interpretations than to peddle them as established truths.

1. The Calculation of Dangerousness in Deadly Assault. On some matters, however, the data appear to speak with more than equivocal authority. The first of these is that empirical studies such as that reported above give the rough outline of a new basis for judging the seriousness of criminal acts of violence - that basis is the objective dangerousness of particular types of behavior. The reader may ask, has not dangerousness always been an important element in the definition and grading of criminal offenses? The answer to this question is that, with respect to deadly attacks, the law has approached the issue of dangerousness indirectly and, as it turns out, incompletely.

Most penal codes now grade violent offenses with a view to a mixture of two factors: the actor's subjective intention and the actual result of an attack. In Illinois, for example, a person is guilty of murder if his intent can be characterized as either intent to kill or to do great bodily harm, or knowledge that his acts create a strong probability of death or great bodily harm, and the result is the death of his victim. If his victim lives, an individual is guilty of attempted murder if he intends to kill. ${ }^{28}$ If he knows that such acts create a strong probability of death or great bodily harm but does not have a specific intent to kill, the individual is guilty only of aggravated battery if his victim lives. ${ }^{28}$

27 In fact, comparisons among different American cities show little, if anything, in the way of a patterned difference. See George P. Newton and Franklin E. Zimring, supra note 1, at 177. The British death rate per 100 reported gun attacks is, however, a good deal higher than that experienced in most American jurisdictions. See Gt. Brit., Home Office, The Use of Firearms in England and Wales (unpublished, 1967).

28 Ill. Rev. Stat., ch. 38, \& 8-4 (1969).

29 Aggravated battery requires "intentionally or knowingly" causing "great bodily 
The important questions in differentiating among murder, attempted murder, and aggravated battery are thus:

(1) did the actor intend to kill?

(2) did death result?

The result of an attack is an incomplete gauge of dangerousness if any element of fortuity determines result, and this seems to be the case. Indeed, one reading of Table 7 in this study and parallel tables in the knife-gun study would characterize homicide in Chicago as a lethal lottery with many times as many players as ultimate losers. The attacker's intent is also an incomplete measure of dangerousness if factors other than intent determine result. This study has shown that another factor, the "instrumentality effect," is an important determinant of the result of an assault.

A third basic question can be asked and answered: In the generality of cases, how likely is it that conduct such as that engaged in by the offender will lead to death? This question is, in practice, answerable by the cautious use of data on violent attacks, although later on I will argue that the present sequence of studies casts some doubt on whether the same can be said for discriminations based on the difference between intention to kill and intention to inflict great bodily harm in most cases of attacks with deadly weapons.

The significance of "objective dangerousness" is subject to some qualifications. First, the present data are clearly deficient as complete measures of objective dangerousness. Data on the distance between attacker and victim are missing from the two studies under discussion. They are important because data on wound location appear too late in the scenario of violence for beforethe-fact dangerousness to be clearly determined. We know only where the attacker hit, not where he aimed. Yet even these data, as displayed in Table 7 , screen out much more fortuity than traditional tests of intent and result.

A second qualification in using before-the-fact calculations of dangerousness is that any rational penal system can make only a limited number of distinctions in the formal grading of violent attacks. Result and intent are still viable distinctions, though in varying degree. Forty-three degrees of violent assault are too many, even for Jeremy Bentham. Some four or five mixtures of result, intent and dangerousness seem the largest number that the penal law can digest. So the question of whether high velocity .38-caliber bullets kill more often than their low velocity .38-caliber cousins can hardly be expected to differentiate offenses. One suspects that, in the task of grading offenses of violence, the law will be hard put to digest effectively even the great difference in death rates between .22 and .38 caliber guns, although this

harm." Ill. Rev. Stat., ch. 38; 812.4 (1969). Attempted murder requires an attack "with intent to commit" the offense of murder. See id. at 8 -4. 
is not clear. Certainly, however, the law can act on the four- or five-to-one difference between death rates in gun and knife attacks.

The second qualification advanced goes a long way toward canceling out the first-if only a limited number of "dangerousness" distinctions can be recognized, then the margin of error from present data is relatively insignificant since the task is the rough grouping of attacks by dangerousness. Particularly if wound location is taken into account only in cases where the attacker had a better-than-usual opportunity to control results, the law's incapacity for fine distinctions diminishes concern with the crudeness of present data.

The third qualification that must be considered is not so easily pushed into the lower rank of present concern. It is one thing to suggest that considerations of objective dangerousness can be integrated into the grading of violent assault and quite another to argue that distinctions based on objective dangerousness, if so integrated, will lead to a substantial saving of lives. If the law could be structured and communicated so that the threat of more severe sanctions would lead people to shoot once rather than twice, use small-caliber rather than large-caliber guns, or, best of all, resort to knives instead of guns, the effect would be a substantial social policy benefit, but there is less reason to hope for a substantial increment of deterrence in this area than in almost any other area of social concern. At the point of attack, the average violent offender seems relatively immune to the threat of criminal sanctions. Unlike many crimes, gun and knife attacks generate a substantial probability that the offender will be arrested ${ }^{30}$ and a relatively high risk of being punished, ${ }^{81}$ because, with the exception of random or robbery-related attacks, the offender is usually easy to identify. Furthermore, almost all of the people who participate in shootings and stabbings are running a substantial risk of killing the object of their attack and thus are already in jeopardy of the law's most severe sanction. At the same time, these attacks typically occur in a context of substantial emotional arousal.

We thus cannot expect every distinction the law wishes to draw to have a substantial influence on the behavior of attackers. For this reason, a strategy of weapons control that focuses on making mechanisms unavailable at the time they may be used in attacks promises a good deal more loss prevention than a gradation of punishment based on the degree of objective dangerousness. $^{32}$ Yet it is not impossible, if the law focuses on one or two central distinctions-the difference between guns and other weapons seems to be a likely

30 See Federal Bureau of Investigation, Uniform Crime Reports 8-10 (1969).

31 See Charles Tittle, Crime Rates and Legal Sanctions, 16 Soc. Probs. 409 (1969).

32 See George P. Newton and Franklin E. Zimring, supro note 1, at chs. 12, 17. 
candidate-that messages conveyed by the grading of offenses might affect attacker behavior at the margins.

But if this kind of process is what we seek, the number of distinctions should be kept small if the message is to be effectively conveyed. And in noting the possibility of some indirect effect of grading on social learning, no basis exists for doubting the initial statement-the prospects for marginal deterrence are far from bright.

There are reasons other than deterrence for considering the objective dangerousness of an attack in making decisions about how seriously an attacker, or a class of attackers, should be punished. To the extent that retributive considerations influence the punishment decision, there is reason for supposing that, as a matter of justice, more dangerous attacks should be punished somewhat more seriously than less dangerous attacks, and that one dimension of the equality of treatment that the law should seek is that attacks of relatively equal dangerousness should, all other things held constant, be treated similarly.

The point I am trying to make is too simple to justify an excursion into the philosophy of punishment. One measure of social dangerousness is the likelihood that a given act, in the generality of cases, will generate loss of life. Therefore, one criterion under a retributive theory of punishment should be the likelihood that a violent event will lead to death. A corollary is that data on objective dangerousness give the retributivist a new index of judging the justness of punishment. Focusing on how many wounds an attacker inflicts, and what kind of instrument be uses, provides an index of probable result less fortuitous than a test that concentrates on result alone.

Yet I am far from confident that a retributivist would feel completely comfortable making judgments about the just degree of punishment from objective dangerousness. ${ }^{33}$ Modern arguments for equality in punishment have emphasized the guilty mind in making claims about equal culpability. The data in the present study make a point that, in large measure, runs against this current. Many of the factors that would be taken into account in judging objective dangerousness are independent of apparent differences in the quality of an attacker's intention. One of H. L. A. Hart's many difficulties with the unequal treatment of attempted and completed crimes is precisely that focusing on result tends to treat those of equal mental culpability in unequal ways. ${ }^{34}$ Yet the same can be said of calculations based on objective dangerousness.

83 Indeed, I am far from sure, in the present array of philosophical positions, of the definition of a "retributivist." Cf. H. L. A. Hart, Punishment and Responsibility; Essays in the Philosophy of Law 231 (1968):

... At least in the broader modern use of the term "retribution," there are many different answers to each of these questions, which may be styled "retributive" and have often earned the title of "retributive" for the theory of which they form part, even if the theory also contains reformative or deterrent elements normally contrasted with retribution.

84 See id. at 129-30. 
My purpose here is to raise the issue rather than resolve it. My own tentative conclusion is that it is at least possible that objective dangerousness could play an important role in a retributivist scale of punishment decisions. In so urging, I point out that we are discussing the use of data on dangerousness only after intent to do harm has been established. I make no implicit claim as to the justice of punishing behavior in the absence of culpable mental states.

Apart from deterrence and retribution, there is an argument to be made that objective dangerousness can help us in dealing with the basic economic problems of law enforcement. Data on the objective dangerousness of different forms of behavior can help in the allocation of scarce penal, prosecutorial, and preventive resources by drawing attention to problems of maximum severity. It is commonly argued, for example, that the addictive, debilitating and criminogenic qualities of heroin make this substance a more appropriate candidate for substantial law enforcement efforts than other drugs. Data on the death rates from attacks can be used in a similar way to focus on the most important problems in the area of violent assaults. Yet the extent to which an attack is likely to kill is something apart from the extent to which that form of attack is a social problem. If one form of attack has a death rate of 50 per 100 attacks but there are only 100 such attacks in the United States, data on the high death rate do not show that the problem presented by that form of attack is more serious than the problems presented by much more common attacks with lower death rates.

Indeed, one conclusion that can be drawn from the sequence of studies here reported is that the intention to wound with an extremely deadly weapon is, in the United States, a more serious problem than unambiguously lethal attacks. There are, I think, perspectives that the present study can bring to the economic problems of deciding whether and how the criminal law should attempt to affect human behavior. But these perspectives come less from a consideration of grading different forms of deadly attack than they do from the broader view of the criminal law as an instrument of loss prevention, for example in the area of weapons control.

I do not want to leave the impression that considerations of objective dangerousness are wholly novel in criminal law. The treatment of objective dangerousness in modern criminal codes varies from situation to situation. Behavior that is dangerous only because it increases the chances that serious but unintended consequences will occur is routinely made criminal. Drunk driving is one offense that seems to fit comfortably into this category. And even those who stress the necessity of intent to do wrong for a proper finding of criminal liability would find awareness of the fact that the actor was driving under the influence of alcohol to be sufficient mens rea (guilty intent) to convict, even when the actor was unaware of any risk that his conduct would lead to further harm. In addition, many penal codes make killings resulting from gross negligence seriously punished offenses. 
It may be the case, however, that criminal codes are more apt to base decisions on criminal liability on the objective dangerousness of behavior when the penalty is low than when the penalty is high. There are striking exceptions to this, such as the felony murder rule, which is alive and apparently flourishing in most jurisdictions, so the more precise point may be that criminal law deals in objective dangerousness in those crimes that do not require that an individual intend or knowingly risk certain consequences. Where the law requires intent, knowledge, or recklessness with respect to death as a threshold for liability, as in the case of non-felony murder, it is suddenly unconcerned with variations in the objective dangerousness of conduct. The origin of the cleavage between intent and dangerousness is unclear. Perhaps there is an implicit assumption that when men can be said either to know or to intend that a result will follow from their conduct, their conduct will almost inevitably produce such a result. Since intent to kill, in most jurisdictions, may be inferred from the act of shooting another with a firearm in an area from which mortal wounds often result, ${ }^{35}$ the presumption that mens rea sufficient to constitute murder inevitably produces a lethal result is incorrect. ${ }^{36}$

35 See, e.g., People v. Sheppard, 402 III. 411, 84 N.E.2d 377 (1949) (one wound-attempted murder, even though the wound was not to an area where death normally results).

36 In part, the modern emphasis on mens rea is a reaction against the theory of "objective liability," a reading of the common law argued by Oliver Wendell Holmes, Jr. It is, I think, appropriate to distinguish that theory from the approach I am suggesting. Holmes described the operation of the "objective theory" of liability in the law of murder in The Common Law 56-57 (1881):

For it is to be remembered that the object of the law is to prevent human life being endangered or taken; and that, although it so far considers blameworthiness and punishing as not to hold a man responsible for consequences which no one, or only some exceptional specialist, could have foreseen, still the reason for this limitation is simply to make a rule which is not too hard for the average member of the community. As the purpose is to compel men to abstain from dangerous conduct and not merely to restrain them from evil inclinations, the law requires them at their peril to know the teaching of common experience, just as it requires them to know the law. Subject to these explanations, it may be said that the test of murder is the degree of danger to life attending the act under the known circumstances of the case.

When Holmes speaks of "the known circumstances of the case," he is referring to circumstances known to the generality of men rather than to the particular accused. He is thus, at least implicitly, not only assuming the culpability of acts that convey a high degree of objective dangerousness, but also maintaining that dangerous acts which unintentionally result in death are as culpable as dangerous acts intended to cause death.

Yet the data reported in this paper on objective dangerousness suggest that if the number of wounds an individual inflicts is any measure of his intention, attacks intended to kill have a higher death rate than more ambiguously motivated attacks, so that there is some basis in fact for differentially judging the two kinds of attack even if the likelihood of death is the only basis for judging the seriousness of attack. A proponent of the Holmesian position might respond that insofar as objective data such as the number of wounds inflicted or even choice of weapons can be taken as indices of intent, the grading of criminal homicide could proceed by placing distinctions on these objective 
2. Applying the Dangerousness Standard: the Problem of the One-Shot Killing. One question raised by the short duration of most fatal and nonfatal assaults is whether the law should allow for a change of heart on the part of offenders and punish single-wound attacks less severely than those carried further. In the criminal law of attempt, an offender's change of heart is usually significant only if it occurs before a criminal result has been achieved. ${ }^{37}$ Were objective dangerousness one of the standards that fed into the grading of deadly assault, more lenient treatment of single-wound attacks might be justifiable on the ground that these attacks are less likely to kill than multiplewound attacks with the same weapons. The question is most problematical when an attack is terminated after a single shot or stabbing and yet the victim dies. Assume that we know little more about intent in such a case than the facts set forth in the previous sentence. The argument for a reduction in the grade of the offense is based on treating the assault that kills in approximately the same way as an equally dangerous but nonfatal attack with the same weapon. To the extent that deterrence seems realistic, the argument is buttressed by the prospects of persuading an individual to pursue leniency by abandoning an attack before it reaches the point of maximum dangerousness; yet death has occurred, and thus we have less reason to suppose that the attacker would allow his victim to live than is the case with the nonfatal singlewound attack. Moreover, the actual social loss is greater: whatever the value in dealing with the chance of death as an abstraction, one must also deal with the fact of death as a reality.

I do not state the issue intending to answer it, because accepting that objective dangerousness is relevant to the grading of deadly assault does not compel a particular answer to the question. Objective dangerousness is only one of many grading principles that can correctly be applied. The usefulness of viewing attacks in terms of objective dangerousness is not that such a view

manifestations rather than on the subjective nature of intent. I am not unsympathetic to this view, but feel that it is not an accurate representation of what Holmes himself would do with the data. My suspicion is that any attack with a deadly weapon would, if death ensues, result in the Holmesian classification of murder. The "objective test" device then becomes one of generating liability for the highest grade of offense rather than making distinctions between types of attack. Fewer than 1 per cent of all robberies result in homicide, and fewer than 1 in 10 robbery attacks kill. Fewer than 10 per cent of attacks with deadly weapons lead to a lethal conclusion. In either case, if "the test of murder is the degree of danger to life attending the act under the known circumstances of the case," any lethal conclusion equals murder. This approach does not make distinctions in deadly attacks; it obliterates them. To apply Holmes to the cases we have been examining, all of the knife and gun attacks to an area that could cause death would be murder when death was the result. Either-it follows that all such nonfatal attacks are attempted murder or the Holmesian emphasis on "objective liability" really makes punishment more dependent on fortuity than almost any other test that could be applied to this class of cases.

37 See Model Penal Code 8 5.01(4), Renunciation of Criminal Purpose (as Defense to Attempt) (Prop. Off. Draft, 1962). 
answers the question whether a single-wound assault should be treated more leniently but that such a perspective raises that question in a new light.

3. Toward a Unification of the Criminal Law of Violence. Another issue to which the present data speak with some persuasive power is whether there is reason to shift from the traditionally separate criminal law consideration of homicide and other offenses of violence to a system that considers the basic category of behavior-that of violent attack-as an important unifying principle.

To be sure, some of the evidence one can marshal for the proposition that there is undue separation in the criminal law's treatment of violence under the present system is impressionistic, even literary. Yet a small literary excursion may be worthwhile. For example, the deadly assaults we have been examining are governed by the provisions of the Illinois Criminal Code of $1961,{ }^{38}$ by many standards one of the most modern and most thoroughly rationalized of penal codes. Homicide, including murder, voluntary manslaughter, involuntary manslaughter, and concealing the death of a bastard is dealt with in Article 9 of that Code. Article 12 of the Code, entitled "bodily harm," defines the offenses most commonly associated with nonfatal serious assault: assault, aggravated assault, battery, aggravated battery and others. The chapters on homicide and bodily harm are separated by provisions defining offenses such as kidnapping, rape, incest, bigamy, prostitution, pimping and obscenity. ${ }^{39}$ One is moved to suggest that this separation is neither accidental nor without significance.

Scholars and draftsmen, both ancient and modern, have tended to consider the law of homicide separately and exhaustively. In the early years of this century, Oscar Warren published a five volume treatise on the law of homicide. ${ }^{40}$ The reported law on the subject of homicide is enormous. This is easy to explain. Murder presents a combination of ultimates, the ultimate offense against human security and the ultimate punishment vested in temporal authority. Particularly in jurisdictions where that punishment is death, one can understand a defendant's motives for producing a high volume of lengthy appeals. At the same time, the lawyer is drawn to homicide by the considerable human instinct, when faced with a choice, to watch the table where the players are betting with $\$ 100$ chips. For these and other reasons, when the great intellects of criminal law scholarship are faced with the possibility of writing a rationale of homicide or one of embezzlement, the choice becomes an obvious one.

The importance of homicide as a social and intellectual problem does not

88 II. Rev. Stat., ch. 38, art. 1-42 (1969).

89 IIl. Rev. Stat., ch. 38, 88 10-1, 11-1, 11-11, 11-12, 11-14, 11-19, 11-20 (1969).

40 Oscar Leroy Warren, On Homicide (1914). 
explain why concern about the law of homicide should not have broadened to a consideration of the great variety of violent threats to human life. In part, one can suggest that the criminal law's emphasis on the quality of an actor's intention has helped maintain this separation. As suggested above, it may have been assumed that a man not only intends the natural and probable consequences of his acts, but intends these consequences to the exclusion of all others, and that in all but a few situations this unambiguous intent will lead to the consequences intended.

How has "homicidal isolationism" handicapped the development of effective criminal law theory? The fast answer is that data and perspectives on objective dangerousness as an index of the significance of conduct are not obtained until nonfatal and fatal attacks with similar weapons and in similar situations are subjected to the unified approach. But the deeper point is the danger of inconsistency and injustice that separation may risk. Real differences in dangerousness are not recognized; artificial distinctions are maintained.

4. Discriminating Intent in Deadly Attack. No area of the criminal law is more notorious for fine and often artificial distinctions between mental states accompanying acts than the law of homicide. Most of this notoriety attaches to the device of distinguishing degrees of culpability for murder by asking whether "premeditation" accompanied the intention to kill."1 While premeditation may have started out as the clearly distinct concept of "lying in wait," as the concept grew the distinction between premeditated and unpremeditated intentional killings became progressively metaphysical. ${ }^{42}$ Distinguishing between killings "with malice" and killings "without malice," if that distinction rests on anything other than the simple intention to kill, is also a task best left to word-magicians or judges and juries trying to conform results in homicide cases to personal instincts about rough justice.

While the concept of premeditation has received the bad press it deserves in academic writings, ${ }^{43}$ most modern writers do express faith in some mens rea distinctions in grading criminal assault. The most popular distinction is between intent to kill, or knowledge that acts will kill, on the one hand, and dangerous acts that seek merely to inflict nonfatal results and are reckless or negligent with respect to fatal consequences. The distinction is an important

41 See Edwin R. Keedy, History of the Pennsylvania Statute Creating Degrees of Murder, 97 U. Pa. L. Rev. 759 (1949).

12 See id. at 773-77.

13 See Benjamin N. Cardozo, What Medicine Can Do for Law, in Law and Literature and Other Essays and Addresses 70, 100 (1931):

What we have is merely a privilege offered to the jury to find the lesser degree .... I have no objection to giving them this dispensing power, but it should be given to them directly and not in a mystifying cloud of words. 
one in the Illinois Criminal Code, for example, because a nonfatal attack with intent to kill is attempted murder, while an attack with any lesser intent is aggravated battery.

But to say that this distinction is important does not mean that it is viable in all cases. There were several hundred cases in one four-month period in Chicago in which an individual wounded another with a firearm in an area where such a wound could prove fatal and three out of four times he only wounded his victim once. Are all of these attacks committed, at the time of the first firing of the weapon, with "intent to kill"? What further data can discriminate attacks intended to kill in this category from other attacks? If we could crawl inside the minds of particular offenders, and if their own emotions were something other than ambiguous about what results were desired, we might obtain some more precise answers and some more precise distinctions. But the combination of the limitations of modern. science and those imposed by modern criminal procedure makes this further step into the offender's mind unlikely, and in the circumstances it is not entirely unfortunate. In judging these serious attacks one either operates with a set of almost conclusive presumptions about intent, or one leaves the question of intention to kill versus intention merely to inflict great bodily harm to the discretion of the trier of fact. A presumption of attempted murder in all firearm and knife attacks would represent a smart comeback for the theory of objective liability, and would in a short time double the number of adult prison inmates in Illinois. Requiring additional evidence for an inference of lethal intent would widen the gap in punishment between similar fatal and nonfatal attacks. The outcome of leaving the determination of crime to the discretion of the trier of fact is more difficult to predict, but is hardly a utopian solution.

In the city of Chicago, then, the distinction between intent to kill and other mental states has some utility in extreme cases, but there are no firm guidelines to provide for the majority of serious assaults.

\section{ConcLusion}

If the weapon-caliber study proves useful to criminal law scholars, it will do so because it injects information about the reality of deadly attacks into an area where such data are rarely deployed. The study appears to say that intent to kill is rarely a helpful way to distinguish among a large number of nonfatal attacks with deadly weapons, and that the criminal law of violence may be artificially separated into fatal and nonfatal containers that hold the same behavioral brew.

As is usually the case, the critical points are easier to make than the constructive ones and enjoy a higher level of confidence. It is by no means clear that focusing on objective dangerousness as one of many factors differentiat- 
ing criminal acts of violence will affect the behavior of potential offenders. It is also inadvisable to assume that considerations of objective dangerousness should be of controlling importance in the definition of offenses. Such considerations are relevant, but other standards, such as result and intention, are also relevant. For that reason the preceding discussion raises a good many more questions than it answers.

One implication of the present exercise may, indeed, be that there can be no such thing as a single "model" penal code. If variations in penal law have any effect at all on behavior, then the proper distinctions in the criminal law of violence should be designed to maximize preventive effects. Different patterns of violence may call for different types of distinctions. And even if the criminal law is whistling in the dark, there is a case to be made, based on consistency and fairness, that distinctions between grades of criminal offenses of violence should parallel the lines of demarcation in the reality of violence. 
HeinOnline -- 1 J. Legal Stud. 1241972 